\title{
Erratum to: User-Centered Design of Geographic Interactive Applications: From High-Level Specification to Code Generation, from Prototypes to Better Specifications
}

\author{
Christophe Marquesuzaà ${ }^{1(\bowtie)}$, Patrick Etcheverry ${ }^{1}$, \\ Sébastien Laborie ${ }^{1}$, Thierry Nodenot ${ }^{1}$, and The Nhan Luong ${ }^{2}$ \\ 1 Université de Pau et des Pays de l'Adour, Laboratoire d'informatique, \\ EA 3000, 64600 Anglet, France \\ \{christophe. marquesuzaa, patrick. etcheverry, sebastien. \\ laborie, thierry.nodenot\}@iutbayonne.univ-pau.fr \\ ${ }^{2}$ Faculty of Computer Science and Engineering, Ho Chi Minh City University \\ of Technology, 268 Ly Thuong Kiet Street, District 10, Ho Chi Minh City, \\ Vietnam \\ nhan@hcmut.edu.vn
}

Erratum to:

Chapter "User-Centered Design of Geographic Interactive Applications: From High-Level Specification to Code Generation, from Prototypes to Better Specifications" in: A. Hameurlain et al. (Eds.): Transactions on Large-Scale Data- and Knowledge-Centered Systems XXXI, LNCS 10140, https://doi.org/10.1007/978-3-662-54173-9_1

The affiliation of the authors Christophe Marquesuzàa, Patrick Etcheverry, Thierry Nodenot, and Sébastien Laborie was incorrectly stated as "LIUPPA - T2iIUT de Bayonne et du Pays Basque, Anglet, France". This has been corrected.

The updated online version of this chapter can be found at https://doi.org/10.1007/978-3-662-54173-9_1 